\title{
Treatment of near-fatal beta blocker and calcium channel blocker intoxication with hyperinsulinemic euglycemia, intravenous lipid emulsions and high doses of norepinephrine
}

BY ANDREJ MARKOTA, EMINA HAJDINJAK, BARBARA RUPNIK, ANDREJA SINKOVIČ

\section{Abstract}

Background. Treatment of combined beta blocker and calcium channel blocker intoxication remains challenging due to a profound and treatment-resistant circulatory collapse. Along with standard therapy (calcium, glucagon, mechanical ventilation, vasopressors), two novel approaches are increasingly being reported as successful: hyperinsulinemic euglycemia and intravenous lipid emulsion.

Case Report. Our patient: a 66-year-old Caucasian male who ingested approximately $450 \mathrm{mg}$ of bisoprolol, $300 \mathrm{mg}$ of amlodipine, $200 \mathrm{mg}$ of doxazosin and smaller amounts of nifedipine, torasemide, acetysaliclic acid and ibuprofen in a suicide attempt. The patient was hypotensive and bradycardic on admission with left-ventricular ejection fraction estimated at 10-15\%. By combining standard therapy (intubation, mechanical ventilation, vasopressors, calcium and glucagon) and new therapies (hyperinsulinemic euglycemia and intravenous lipid emulsions) in a stepwise approach we normalized systolic function and treated bradycardia 
within 2 hours of admission. However, severe hypotension persisted requiring extremely high doses of norepinephrine $(14 \mathrm{mcg} / \mathrm{kg} / \mathrm{min})$ and vasopressin $(0.03$ $\mathrm{U} / \mathrm{min}$ ) to maintain his blood pressure over the following three days. He was discharged home after prolonged in-hospital treatment and rehabilitation (62 days) and extensive physical and psychiatric rehabilitation.

Why should an emergency physician be aware of this? Aggressive medical therapy including hyperinsulinemic euglycemia, intravenous lipid emulsions and high doses of norepinephrine could be considered for multidrug intoxication with a predominant clinical picture of beta blocker and calcium channel blocker intoxication in patients presenting with severe hemodynamic compromise.

Key words: poisoning, emergency treatment, complementary therapies

\section{Introduction}

Traditionally, therapy for beta blocker (BB) and calcium channel blocker (CCB) intoxication consisted of calcium and glucagon administration and supportive measures. (1) There are reports of successful use of extracorporeal support in cases of refractory cardiogenic shock. A number of papers have been published describing successful treatment with hyperinsulinemic euglycemia (HIEG) and intravenous lipid emulsions (ILE). (1-5) Animal studies support the use of HIEG and ILE, however optimal timing, duration and dosage of both of these therapies, especially ILE, remains unknown. (4,6-8) We present a case of successful treatment of a near-fatal multidrug intoxication, with BB and CCB intoxication dominating the clinical presentation.

Extremely high doses of norepinephrine and vasopressin were required to maintain our patient's blood pressure. Temporary transvenous pacing or extracorporeal support were not used.

\section{Case report}

A 66-year-old male with a history of depression and arterial hypertension was admitted to the intensive care unit (ICU) about 2 hours after taking approximately $450 \mathrm{mg}$ of bisoprolol, $300 \mathrm{mg}$ of amlodipine, $200 \mathrm{mg}$ of doxazosin, $600 \mathrm{mg}$ of nifedipine, $150 \mathrm{mg}$ of torasemide, $4000 \mathrm{mg}$ of acetysaliclic acid and $5000 \mathrm{mg}$ of 
ibuprofen in a suicide attempt. We were able to ascertain quantities of ingested drugs heteroanamnestically. He was unconscious, hypotensive (blood pressure 45/30 $\mathrm{mmHg}$ ) and bradycardic (sinus bradycardia with heart rate 30 beats per minute (bpm)) on admission. During the peri-intubation period he was supported with 4 boluses (o.1 mg each) of epinephrine. Bedside echocardiography revealed severe left-ventricular systolic dysfunction. Ejection fraction was estimated at 1015\% and velocity-time interval of left ventricle outflow tract (VTILVOT) was $9 \mathrm{~cm}$. Arterial and central venous catheterization was performed next. Initial $10 \mathrm{ml}$ of $10 \%$ calcium-gluconate resulted in an increase in heart rate to $40-45 \mathrm{bpm}$ and three more infusions of calcium-gluconate were used during arterial and central venous cannulation. Simultaneously, $5 \mathrm{mg}$ of glucagon was infused, followed by two additional glucagon infusions ( $5 \mathrm{mg}$ each). A total of $1500 \mathrm{ml}$ of normal saline was infused in the first 30 min without any additional effect on blood pressure. Norepinephrine was started as soon as the central venous catheter was in place. Simultaneously, dobutamine infusion (10 $\mathrm{mcg} / \mathrm{kg} / \mathrm{min}$ ) was initiated, without a notable increase in heart rate or ejection fraction. We applied activated charcoal (50 g) after gastric lavage. Qualitative laboratory analysis of returning fluid confirmed the presence of the above mentioned drugs.

After the above therapy, heart rate increased to about 40-50 bpm, however, infusions of calcium and glucagon were needed to maintain it. We used HIEG as next line of therapy. A bolus dose (1 IU/kg) was followed by continuous infusion (1 $\mathrm{IU} / \mathrm{kg} / \mathrm{h})$. Heart rate stabilized at about $70-80 \mathrm{bpm} \mathrm{h}$ after admission and no more infusions of calcium or glucagon was required. ILE was used next. $100 \mathrm{ml}$ of $20 \%$ lipid emulsion was infused over $5 \mathrm{~min}$ and a further $150 \mathrm{ml}$ over $60 \mathrm{~min}$. After 100 $\mathrm{ml}$ of ILE, the patient's left-ventricular ejection fraction normalized (estimated at more than 50\%, VTILVOT $16 \mathrm{~cm}$, cardiac output estimated at $8 \mathrm{l} / \mathrm{min})$. In-spite of this, increasing doses of norepinephrine were required to maintain his mean arterial pressure at $60 \mathrm{mmHg}$. Vasopressin, at $0.03 \mathrm{U} / \mathrm{min}$, was added, once the norepinephrine infusion rate reached $0.5 \mathrm{mcg} / \mathrm{kg} / \mathrm{min}$. In the following hours, a further increase of the norepinephrine dose was required, reaching 14 $\mathrm{mcg} / \mathrm{kg} / \mathrm{min}$ after about 3 hours, after which his blood pressure stabilized.

Our patient's clinical data including therapy, central venous oxygen saturation, urine output, mean arterial pressure (MAP) and heart rate in the first 6 hours are outlined in figure 1. Severe metabolic acidosis (pH 7.12, partial pressure of carbon dioxide $\left(\mathrm{pCO}_{2}\right) 5.49 \mathrm{kPa}$, partial pressure of oxygen $\left(\mathrm{pO}_{2}\right) 10.9 \mathrm{kPa}$, bicarbonate 
$\left(\mathrm{HCO}_{3}\right) 10.5 \mathrm{kPa}$, oxygen saturation $92 \%$, lactate $\left.8.5 \mathrm{mmol} / \mathrm{l}\right)$ was present on admission. Creatinine was elevated to $185 \mu \mathrm{mol} / \mathrm{L}$, C-reactive protein was $<3 \mathrm{mg} / \mathrm{L}$ and concentration of acetylsalicylic acid on admission was $167 \mathrm{mcg} / \mathrm{ml}$ (within normal range). We observed no major abnormalities in other laboratory tests on admission.

24 hours after admission, norepinephrine infusion could be decreased. HIEG therapy was continued until day 3 , when the patient was successfully weaned off both HIEG and vasopressin. He required $0.6 \mathrm{mcg} / \mathrm{kg} / \mathrm{min}$ of norepinephrine on day 3 and $0.1 \mathrm{mcg} / \mathrm{kg} / \mathrm{min}$ on day 7 . Norepinephrine infusion was discontinued on day 17 , and the patient was extubated on day 18 and discharged from the ICU on day 25. After having completed psychiatric rehabilitation he was discharged home without neurological sequelae after 62 days.

\section{Discussion}

In our patient, severe BB and CCB intoxication caused profound and resistant circulatory collapse. Immediately after admission, we maintained his blood pressure using standard therapy with calcium, glucagon and boluses of epinephrine. This has been described (5) and was partially effective in our case. Because of severe hemodynamic compromise we progressed to HIEG and ILE. HIEG improves cardiac contractility and vascular resistance. (6) Because of inhibition of calcium channels, CCB intoxication causes reduction of glucose uptake and consequent decrease in myocardial contractility and loss of vascular smooth muscle cell function. Animal studies of CCB intoxication have favored HIEG over standard therapy (calcium, glucagon or epinephrine). (6) The optimal dose of insulin in HIEG is not known. Reported doses are 0.5 to $1 \mathrm{IU} / \mathrm{kg}$ bolus, followed by $0.5^{-1} \mathrm{IU} / \mathrm{kg} / \mathrm{h}$ infusion. Hypoglycemia and hypokalemia are the main adverse effects. $(4,6)$ ILE is a novel treatment for lipophilic drug poisonings, which was first described in local anesthetic poisoning and more recently in cases of other lipophilic drug poisonings, including BB and CCB. $(7,8)$ Animal models of CGB poisoning suggest survival benefit of ILE over standard therapy. (7) Main adverse effects are development of acute lung injury and allergic reactions. $(2,7,8)$ Successful concurrent use of HIEG and ILE has been described in drug-induced cardiogenic shock. (2)

Mechanical support with either intra-aortic balloon pump or veno-arterial extra- 
corporeal membrane oxygenation (VA ECMO) was considered from the outset. (9) We decided against it, once systolic function improved after the instituted medical therapy. Use of these devices in vasodilatory shock is questionable. (9) We attributed severe hypotension to ingestion of multiple antihypertensives (5) and treated it with dual vasopressor therapy in high doses. There are reports of successful and safe use of norepinephrine at doses higher than $4 \mathrm{mcg} / \mathrm{kg} / \mathrm{min}$. (10) Our patient's fingertips remained warm and well perfused throughout treatment.

In conclusion, aggressive medical therapy for severe multi-drug intoxication with a predominant clinical picture of BB and CCB intoxication including calcium, glucagon, HIEG and ILE, while providing support with norepinephrine and vasopressin is plausible and could be considered early in patients presenting with severe hemodynamic compromise.

Figure 1. Clinical data in the first 6 hours of treatment. HR, heart rate; MAP, mean arterial pressure; $\mathrm{ScvO}_{2}$, central venous oxygen saturation.

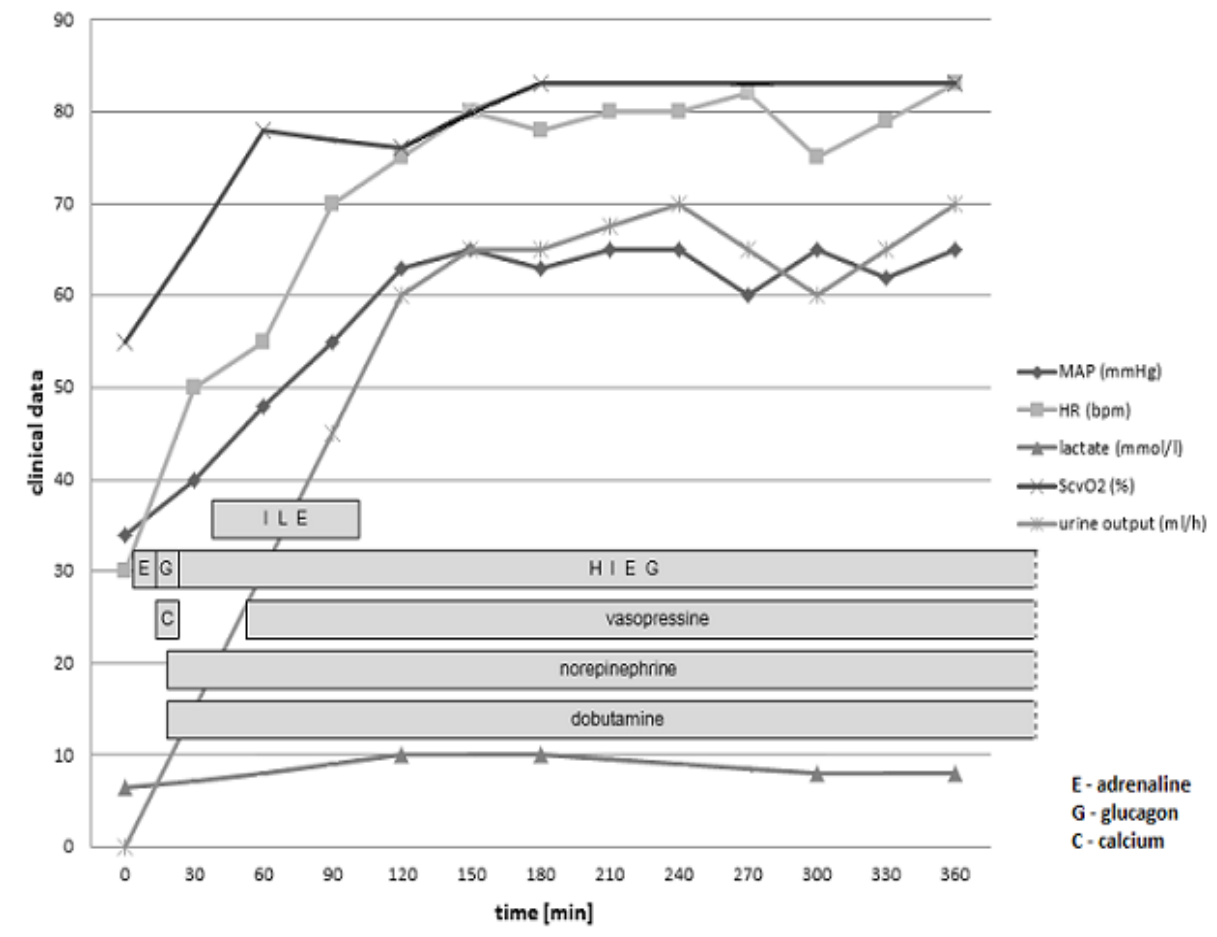




\section{References}

1. Truitt CA, Brooks DE, Dommer P, Lovecchio F. Outcomes of unintentional betablocker or calcium channel blocker overdoses: a retrospective review of poison center data.J Med Toxicol 2012;8:135-9.

2. Stellpflug SJ, Harris CR, Engebretsen KM, Cole JB, Holger JS. Intentional overdose with cardiac arrest treated with intravenous fat emulsion and high-dose insulin. Clin Toxicol (Phila) 2010;48:227-9.

3. Azendour H, Belyamani L, Atmani M, Balkhi H, Haimeur C. Severe amlodipine intoxication treated by hyperinsulinemia euglycemia therapy.J Emerg Med 2010;38:33-5.

4. Engebretsen KM, Kaczmarek KM, Morgan J, Holger JS. High-dose insulin therapy in beta-blocker and calcium channel-blocker poisoning. Clin Toxicol (Phila) 2011;49:277-83.

5. Kerns $\mathrm{W}_{2}{ }^{\text {nd }}$. Management of beta-adrenergic blocker and calcium channel antagonist toxicity. Emerg Med Clin North Am 2007;25:309-31.

6. Lheureux PER, Zahir S, Gris M, Derrey AS, Penaloza A. Bench-to-bedside review: Hyperinsulinaemia/euglycaemia therapy in the management of overdose of calcium-channel blockers. Crit Care 2006;10:212.

7. Cave G, Harvey M, Castle C. The role of fat emulsion therapy in a rodent model of propranolol toxicity: a preliminary study. J Med Toxicol 2006;2:4-7.

8. Weinberg GL. Lipid emulsion infusion: resuscitation for local anesthetic and other drug overdose. Anesthesiology 2012;117:180-7.

9. Masson R, Colas V, Parienti.JJ, Lehoux P, Massetti M, Charbonneau P, et al. A comparison of survival with and without extracorporeal life support treatment for severe poisoning due to drug intoxication. Resuscitation 2012;83:1413-7.

10. Katsaragakis S, Kapralou A, Theodorou D, Markogiannakis H, Larentzakis A, Stamou KM, et al. Refractory septic shock: efficacy and safety of very high doses of norepinephrine. Methods Find Exp Clin Pharmacol 2006;28:307-13.

\footnotetext{
Andrej Markota, Andreja Sinkovič

Medical Intensive Care Unit, University Medical Centre Maribor, Ljubljanska 5, 2000 Maribor, Slovenia Emina Hajdinjak

Emergency Medicine Service, Community Health Centre Ljubljana, Metelkova 9, 1000 Ljubljana, Slovenia Barbara Rupnik

Department of Anesthesiology, Intensive Care and Pain Management, University Medical Centre Maribor, Ljubljanska 5, 2000 Maribor, Slovenia

Corresponding author:

Barbara Rupnik

Department of Anesthesiology, Intensive Care and Pain Management
} 
SIGNA VITAE 2015; 10(1): 144 - 150

University Medical Centre Maribor Ljubljanska 5. 2000 Maribor, Slovenia Phone: oo 38641569902

E-mail: barbara.rupnik@gmail.com 